REVIEW

\title{
Can polyclonal intravenous immunoglobulin limit cytokine mediated cerebral damage and chronic lung disease in preterm infants?
}

\author{
P V Mohan, W Tarnow-Mordi, B Stenson, P Brocklehurst, K Haque, V Cavendish, A Cust
}

Arch Dis Child Fetal Neonatal Ed 2004;89:F5-F8

Recent evidence suggests that inflammatory cytokines may play an important role in cerebral and pulmonary injury, especially in preterm infants. Immunomodulatory agents may help to limit such injury by reducing inflammation. Immunoglobulin has multiple anti-inflammatory properties and can modulate the inflammatory cytokine response. New evidence is required to test the hypotheses that prophylaxis or treatment with intravenous immunoglobulin may limit such inflammatory damage.

See end of article for authors' affiliations

\section{Correspondence to:}

Dr Mohan, Department of Paediatrics, Baylor College of Medicine, 1 Baylor

Plaza, Houston, TX 77025

USA; suseela12@

hotmail.com

Accepted

8 December 2002

\section{PERINATAL INFECTION AND ADVERSE NEONATAL OUTCOME}

Chorioamnionitis and prolonged rupture of membranes increase the risk of cerebral palsy in preterm infants. ${ }^{1}$ In a meta-analysis of 26 studies in preterm infants, clinical chorioamnionitis trebled the risk of cystic periventricular leucomalacia and doubled the risk of cerebral palsy, even when the analysis was adjusted for gestational age. In a meta-analysis in term infants, clinical chorioamnionitis increased cerebral palsy nearly fivefold. ${ }^{2}$ In one study, infants born at term after chorioamnionitis had 9 times neonatal sepsis increased the risk of cerebral palsy fourfold, after adjustment for gestational age. ${ }^{4}$

\section{THE INFLAMMATORY CYTOKINE RESPONSE}

Infection initiates a complex immune process, which includes antigen detection, $\mathrm{T}$ cell activation and proliferation, and release of cytokines. Cytokines are low molecular mass proteins, which mediate cell growth, inflammation, immunity, differentiation, migration, and repair. They regulate the amplitude and the duration of the inflammatory response and include interleukins (IL), interferons, colony stimulating factors, tumour necrosis factor (TNF) $\alpha$ among others.

\section{INFLAMMATORY CYTOKINES AND BRAIN INJURY}

Elevated cytokine levels in blood spots collected in the newborn period can predict the later greater risk of cerebral palsy. ${ }^{3}$ In another, development of cerebral palsy. ${ }^{5}$ Cerebral palsy was strongly associated with antenatal exposure to intra-amniotic inflammation, as evidenced by increased IL6, IL8, and white cells in the amniotic fluid and a systemic fetal inflammatory response, indicated by funisitis. ${ }^{6}$ In autopsy specimens, local expression of proinflammatory cytokines is increased in brains with periventricular leucomalacia ${ }^{78}$ and is mainly detected in hypertrophic astrocytes and microglial cells. Cytokine release is also observed after hypoxiaischaemia and trauma, which are important contributors to perinatal brain damage..$^{10}$ In a prospective study of 50 infants born before 30 weeks gestation, $36 \%$ had cerebral lesions on magnetic resonance imaging that were associated with an inflammatory response to prenatal infection, as evidenced by increased umbilical cord blood cytokines, $\mathrm{T}$ cell activation, raised maternal $\mathrm{C}$ reactive protein, and preterm prolonged rupture of membranes. ${ }^{11}$

Furthermore, the idea that neonates have a reduced ability to produce proinflammatory cytokines $^{12}$ has been challenged by recent studies. A higher percentage of monocytes positive for the cytokines IL6 and IL8 has been reported in term and preterm infants than in adults, and, in very low birthweight infants with proven infection, the frequency of cytokine positive cells was substantially greater than in infants without infection. ${ }^{13}$ Preliminary data indicate that preterm fetuses can produce substantial quantities of proinflammatory cytokines. The preterm fetal inflammatory response may play a greater role in the pathogenesis of cerebral lesions than previously suspected. ${ }^{14}$

\section{INFLAMMATORY CYTOKINES AND LUNG INJURY}

There is increasing evidence that proinflammatory cytokines may be a common pathway in lung inflammation, which can results in chronic lung disease (CLD). ${ }^{15}$ Intrauterine inflammation, as evidenced by increased amniotic fluid IL6, $\mathrm{TNF} \alpha$, ILl, and IL8 ${ }^{16}$ and increased umbilical cord blood IL6, ${ }^{17}$ can predict the development of CLD. Inflammatory cytokines, especially ILl, are increased in the tracheal lavage fluid after

Abbreviations: CLD, chronic lung disease; IL, interleukin; IVIG, intravenous immunoglobulin; TNF, tumour necrosis factor 
chorioamnionitis on the first day after birth in those who develop CLD, ${ }^{18}$ suggesting the importance of intrauterine inflammation, perhaps initiated by uteroplacental infection. ${ }^{19}$ Postnatal infection or colonisation of the airways may also cause an inflammatory response, which could contribute to CLD. $^{20}$

\section{CYTOKINES AND TISSUE INJURY: CAUSE OR EFFECT?}

Animal models have shown that cytokines can do cause brain damage. ${ }^{21-23}$ Blocking the effect of cytokines by ILl receptor antagonism, platelet activating factor antagonism, or neutrophil depletion can limit brain damage. ${ }^{21}$ The association cannot be dismissed as an epiphenomenon, and the evidence suggests that inflammatory cytokines lead to tissue injury in humans.

However, the mechanisms of tissue damage associated with elevated cytokine levels are unclear. This may be a direct effect, or caused by stimulation of other immune mechanisms-for example, complement activation or migration and degranulation of neutrophils with release of matrix metalloproteinases. Evidence of a direct effect comes from elegant observations in transgenic mice that overexpressed IL6 from birth. These animals did not develop a blood-brain barrier and at 6 months had evidence of severe injury to the central nervous system. ${ }^{23}$ In humans, IL6 genotypes may increase the risk of septicaemia in preterm neonates, ${ }^{24}$ and genetic polymorphisms can affect the development of CLD. ${ }^{25}$

\section{IMMUNOMODULATORY AGENTS}

Whatever the mechanism of cerebral and pulmonary injury, the apparent importance of inflammation in their pathogenesis makes immunomodulatory therapy an attractive proposition. Dammann and Leviton ${ }^{26}$ have proposed a model of perinatal cerebral damage with a balance between developmental insult and protective components. They postulated the existence of developmentally regulated endogenous neuroprotective agents, which they have named "oligotrophins". There is considerable evidence that immunoglobulin may fulfil similar functions, as it has important immunomodulatory effects that modify inflammatory disease processes in man.

\section{CLINICAL EVIDENCE FOR HIGH DOSE POLYCLONAL INTRAVENOUS IMMUNOGLOBULIN (IVIG) AS AN IMMUNOMODULATORY AGENT}

High dose polyclonal IVIG is effective in the treatment of inflammatory disorders of the nervous system in adults. In randomised trials, IVIG reduced clinical disability in GuillainBarre syndrome, ${ }^{27}$ chronic inflammatory demyelinating polyneuropathy, ${ }^{28}$ and multifocal motor neuropathy. ${ }^{29}$ A systematic review of trials in multiple sclerosis suggests that IVIG reduced the relative risk of relapses by $21-28 \%$ (relative risk (RR) $0.79,95 \%$ confidence interval (CI) 0.49 to 0.92 ; RR 0.72 , $95 \%$ CI 0.54 to 0.97$).{ }^{30-32}$ In randomised controlled trials evaluating serial magnetic resonance imaging in multiple sclerosis, brain lesions decreased in size and number after IVIG treatment. ${ }^{33}$ These studies suggest that IVIG can reduce cerebral inflammation and ameliorate pre-existing cerebral lesions.

In a systematic review of 11 randomised controlled trials with 492 patients of all ages with sepsis or septic shock, polyclonal IVIG reduced mortality by $36 \%$, with a narrow confidence interval (RR $0.64,95 \%$ CI 0.51 to 0.80$).{ }^{35}$ This highly significant result may also, in part, reflect its multifactorial anti-inflammatory effects.

\section{POTENTIAL MECHANISMS OF POLYCLONAL IMMUNOGLOBULIN AS AN IMMUNOMODULATORY AGENT}

IVIG modulates cytokine production in vitro ${ }^{36}$ and in vivo, and downregulates the ILl system. ${ }^{37}$ IVIG contains antibodies directed against IL1, IL6, and interferons $\alpha, \beta$, and $\gamma$, which modulate the cytokine cascade. ${ }^{38}$ IVIG has a cytoprotective effect on TNF $\alpha$ induced cell death in fibroblasts. ${ }^{39}$ IVIG regulates $\mathrm{B}$ cell differentiation and immunoglobulin production $^{40}$ and can regulate CD8 mediated suppressor or cytotoxic T cell function. ${ }^{41}$ IVIG causes degranulation and impairment of migration and reduces infiltration of neutrophils in inflamed tissues. ${ }^{42}$ IgG also stimulates inactivation of C3bcontaining complexes thereby reducing $\mathrm{C} 3$ activation $^{43}$ and complement mediated inflammation.

IVIG may play an important role in local central nervous system inflammatory processes and has been shown to increase nitric oxide production by cultured rat microglia. ${ }^{44}$ Microglial phagocytosis is inhibited by IVIG, which can protect oligodendroglia from antibody mediated complement injury. ${ }^{45}$ Monoclonal antibodies directed against certain surface antigens on the oligodendroglia can enhance remyelination in virus mediated demyelination. These antibodies may be a component of the normal repertoire of endogenous immunoglobulin (and IVIG preparations). ${ }^{46}$

\section{PRETERM INFANTS AND IMMUNOGLOBULINS}

Transport of immunoglobulin from the mother to the fetus across the placenta occurs after 32 weeks, and significant endogenous synthesis does not occur until after 24 weeks after birth. ${ }^{47}$ If the mother does not have antibody to specific pathogens, then pathogen specific antibodies are also deficient in the newborn. ${ }^{48}$ Therefore preterm infants, especially those born before 32 weeks, could be quantitatively and qualitatively deficient in immunoglobulins. Preterm infants are at high risk for infection, with subsequent inflammatory damage to the brain and the lungs. Therefore a physiological basis exists for the use of intravenous immunoglobulins in preterm infants for prevention or treatment of neonatal infections. IVIG, being a broad spectrum immunomodulating agent, may help to reduce the inflammatory response and limit organ damage. However, there is currently little evidence from controlled trials to support the hypothesis that IVIG limits neonatal inflammatory damage. In the Cochrane reviews of trials using IVIG for prophylaxis in preterm and or low birthweight infants and for treatment of clinical or proven sepsis, there are no data on periventricular leucomalacia and very little on CLD or neurodevelopmental outcome. ${ }^{49} 50$ Furthermore the doses of IVIG used were lower than in adult studies, which typically start with $2 \mathrm{~g} / \mathrm{kg}$, followed by repeat doses of $400 \mathrm{mg} / \mathrm{kg}$ at one or two month intervals. An ideal randomised controlled trial to test the hypothesis that IVIG can reduce inflammatory damage should randomise neonates at high risk of central nervous system or pulmonary injury to prophylactic, repeated high dose IVIG or placebo. It should include short term outcomes of serial cytokine response, $\mathrm{T}$ cell activation, magnetic resonance imaging of the brain, oxygen dependency, and long term outcomes of neurodevelopmental and cognitive impairment.

INIS, the international neonatal immunotherapy study, is a large randomised placebo controlled trial (http:// www.npeu.ox.ac.uk/INIS.htm) of IVIG, in a cumulative dose of $1 \mathrm{~g} / \mathrm{kg}$, as an adjunct to antibiotic treatment in proven or suspected neonatal sepsis. It does not therefore fulfil the criteria for an ideal test of these hypotheses. However, it may provide preliminary insights, particularly in specific subgroups. These include infants born after chorioamnionitis, prolonged rupture of membranes, or increased maternal $\mathrm{C}$ 
reactive protein, who are at high risk of cerebral inflammatory damage. ${ }^{2} 115152$

\section{OTHER IMMUNOMODULATORY AGENTS}

Pentoxifylline, a methylxanthine and a phosphodiesterase inhibitor, inhibits the production of TNF $\alpha$ and has been shown to have beneficial biological effects in sepsis. ${ }^{53}$ It was found to reduce neonatal mortality when used as an adjunct in neonatal sepsis, ${ }^{54}$ and in a nebulised form may be useful in CLD. ${ }^{55}$ In animal models, antagonism of platelet activating factor, neutrophil depletion, and ILl receptor antagonism have all been effective in limiting brain damage ${ }^{21}$ and so have inhibitors of matrix metalloproteinases..$^{56}$ These immunomodulatory agents have a narrow spectrum of activity and involve inhibitory effects of one or a few cytokines in the inflammatory cascade. They may therefore not be fully effective in improving outcomes in clinical trials.

Antenatal steroid prophylaxis for preterm birth reduces neonatal mortality (odds ratio (OR) $0.60,95 \%$ CI 0.48 to 0.75 ) and nearly halves the incidence of respiratory distress syndrome (OR 0.53 , 95\% CI 0.44 to 0.63 )..$^{57}$ The use of antenatal steroids has been associated with a reduction in the incidence of cerebral white matter lesions in very low birthweight neonates ${ }^{58}$ and a reduction in cerebral palsy by more than half.59 Steroids have a broad spectrum antiinflammatory effect, and the reduction in brain damage may in part be due to an anti-inflammatory effect. However, the use of postnatal steroids for CLD when the brain is still immature has been associated with an adverse neurological outcome. ${ }^{60}$ Unlike steroids, IVIG has a broad spectrum antiinflammatory effect which so far seems to be free of serious side effects and is hence very promising.

\section{CONCLUSIONS}

There is consistent evidence linking perinatal infection and adverse neonatal outcome. Infection leads to an inflammatory response that may be responsible for initiating and prolonging tissue injury. Modulation of inflammation is a relatively new strategy for preventing or treating such injury. New evidence is needed to evaluate the role of IVIG as a nonsteroidal anti-inflammatory agent that may reduce neonatal mortality and morbidity.

\section{Authors' affiliations \\ P V Mohan, Department of Paediatrics, Baylor College of Medicine, Houston, TX 77025, USA}

W Tarnow-Mordi, Department of Neonatology, Westmead Hospital and Children's Hospital at Westmead, Sydney, NSW 2145, Australia B Stenson, The Royal infirmary of Edinburgh at Little France, Edinburgh, EHI 6 4SU, Scotland, UK

P Brocklehurst, National Perinatal Epidemiology Unit, Institute of Health Services, Oxford, OX3 7LF, UK

K Haque, Department of Child Health, Queen Mary's Hospital for Children, Carshalton, Surrey SM5 IAA, UK

V Cavendish, Department of Clinical Sciences at North Bristol (Orthopaedic Surgery), University of Bristol, Bristol BS10 5NB, UK A Cust, NHMRC Clinical Trials Centre, University of Sydney, Sydney, NSW 2006, Australia

\section{REFERENCES}

1 Murphy DJ, Sellers S, MacKenzie IZ, et al. Case-control study of antenatal and intrapartum risk factors for cerebral palsy in very preterm singleton babies. Lancet 1995;346:1449-54.

2 Wu YW, Colford JM Jr. Chorioamnionitis as a risk factor for cerebral palsy: a meta-analysis. JAMA 2000;284:1417-24.

3 Grether JK, Nelson KB. Maternal infection and cerebral palsy in infants of normal birth weight. JAMA 1997;278:207-11

4 Murphy DJ, Hope PL, Johnson A. Neonatal risk factors for cerebral palsy in very preterm babies: case-control study. BMJ 1997;314:404-8.

5 Nelson KB, Dambrosia JM, Grether JK, et al. Neonatal cytokines and coagulation factors in children with cerebral palsy. Ann Neurol 1998;44:665-75
6 Yoon BH, Romero R, Park JS, et al. Fetal exposure to an intra-amniotic inflammation and the development of cerebral palsy at the age of three years. Am J Obstet Gynecol 2000;182:675-81.

7 Yoon BH, Romero R, Kim CJ, et al. High expression of tumor necrosis factoralpha and interleukin-6 in periventricular leukomalacia. Am J Obstet Gynecol 1997; 177:406-11

8 Kadhim H, Tabarki B, Verellen G, et al. Inflammatory cytokines in the pathogenesis of periventricular leukomalacia. Neurology 2001;56:1278-84.

9 Savman K, Blennow M, Gustafson K, et al. Cytokine response in cerebrospinal fluid after birth asphyxia. Pediatr Res 1998;43:746-51.

10 Whalen MJ, Carlos TM, Kochanek PM, et al. Interleukin 8 is increased in cerebro-spinal fluid in children with severe head injury. Crit Care Med 2000;28:929-34

11 Duggan PJ, Maalouf EF, Watts TL, et al. Intra-uterine T-cell activation and increased pro-inflammatory cytokine concentrations in pre-term infants with cerebral lesions. Lancet 2001;358:1699-1700.

12 Kilpatrick L, Harris MC. Cytokines and the inflammatory response. In: Polin RA, Fox WW, eds. Fetal and neonatal physiology. Philadelphia: WB saunders, 1997:1967-78.

13 Schultz C, Rott C, Temming P, et al. Enhanced interleukin-6 and interleukin-8 synthesis in term and preterm infants. Pediatr Res 2002;51:317-22.

14 Schultz C, Temming P, Gembruch U, et al. Polyclonal intravenous immunoglobulin to prevent brain injury in preterm infants. Lancet 2002;359:1522-3.

15 Speer CP. Inflammatory mechanisms in neonatal chronic lung disease. Eur J Pediatr 1999;158(suppl 1):18-22.

16 Yoon BH, Romero R, Jun JK, et al. Amniotic fluid cytokines (interleukin-6, tumor necrosis factor- $\alpha$, interleukin $1 \beta$, and interleukin 8) and the risk for the development of bronchopulmonary dysplasia. Am J Obstet Gynecol 1997; 177:825-30.

17 Yoon BH, Romero R, Kim KS, et al. A systemic fetal inflammatory response and the development of bronchopulmonary dysplasia. Am J Obstet Gynecol 1999;181:773-9.

18 Watterburg KL, Demers LM, Scott SM, et al. Chorioamnionitis and early lung inflammation in infants in whom bronchopulmonary dysplasia develops. Pediatrics 1996;96:210-5.

19 Groneck P, Schmale J, Soditt V, et al. Bronchoalveolar inflammation following airway infection in preterm infants with chronic lung disease. Pediatr Pulmonol 2001;31:331-8.

20 Groneck P, Goetze-Speer B, Speer CP. Inflammatory bronchopulmonary response of preterm infants with microbial colonisation of the airways at birth. Arch Dis Child Fetal Neonatal Ed 1996;74:F51-5.

21 Silverstein FS, Barks JD, Hagan P, et al. Cytokines and perinatal brain injury. Neurochem Int 1997;30:375-83.

22 Esmon CT. Does inflammation contribute to thrombotic events? Haemostasis 2000;30(suppl 2):34-40.

23 Brett FM, Mizisin AP, Powell HC, et al. Evolution of neuropathological abnormalities associated with blood-brain barrier breakdown in transgenic mice expressing interleukin-6 in astrocytes. J Neuropathol Exp Neurol 1995;54:766-75.

24 Harding D, Montgomery H, Dhamrait S, et al. Does IL-6-174 genotype predict the development of septicaemia in pre-term infants? [abstract] Arch Dis Child 2002;86(suppl 1):A16.

25 Beresford MW, Drury JA, Mountford R, et al. Variation in genetic polymorphisms and chronic lung disease. [abstract] Arch Dis Child 2002;86(suppl 1):A17.

26 Dammann O, Leviton A. Brain damage in preterm newborns: might enhancement of developmentally regulated endogenous protection open a door for prevention? Pediatrics 1999:104:541-50.

27 Plasma Exchange/Sandoglobulin Gullian-Barre Syndrome Trial Group. Randomised trial of plasma exchange, intravenous immunoglobulin and combined treatments in Guillain-Barre syndrome. Lancet 1997:349:225-30

28 Hahn F, Bolton CF, Zochodne D, et al. Intravenous immunoglobulin treatment in chronic inflammatory demyelinating polyneuropathy: a double blind, placebo controlled, cross-over study. Brain 1996;119:1067-77.

29 Van den Berg LH, Kerkhoff H, Oey PL, et al. Treatment of multifocal motor neuropathy with high dose intravenous immunoglobulins: a double blind placebo controlled study. J Neurol Neurosurg Psychiatry 1995;59:248-52.

30 Clegg A, Bryant J, Milne R. Disease-modifying drugs for multiple sclerosis: a rapid and systematic review. Health Technol Assess 2000;4:1-101.

31 Achiron A, Gabbay U, Gilad R, et al. Intravenous immunoglobulin treatment in multiple sclerosis. Effect on relapses. Neurology 1998;50:398-402.

32 Fazekas F, Deisenhammer F, Strasser Fuchs S, et al. Randomised placebocontrolled trial of monthly intravenous immunoglobulin therapy in relapsingremitting multiple sclerosis. Lancet 1997;349:589-93.

33 Sorensen PS, Wanscher B, Jensen CV, et al. Intravenous immunoglobulin G reduces MRI activity in relapsing multiple sclerosis. Neurology 1998:50:1273-81.

34 Teksam M, Tali T, Kocer B, et al. Qualitative and quantitative volumetric evaluation of the efficacy of intravenous immunoglobulin in multiple sclerosis: preliminary report. Neuroradiology 2000;42:885-9.

35 Alejandria MM, Lansang MA, Dans LF, et al. Intravenous immunoglobulin for treating sepsis and septic shock [Cochrane review]. In: The Cochrane Library. Oxford: Oxford Update Software, 2002:issue 4

36 Andersson J, Skansen-Saphir U, Sparrelid E, et al. Intravenous immunoglobulin affects cytokine production in T lymphocytes and monocytes/ macrophages. Clin Exp Immunol 1996;104(suppl 1):10-20. 
37 Aukrust $\mathbf{P}$, Muller $\mathrm{F}$, Svenson $\mathrm{M}$, et al. Administration of intravenous immunoglobulin (IVIG) in vivo downregulatory effects of the IL-1 system. Clin Exp Immunol 1999;115:136-43.

38 Ross $C$, Svenson $M$, Hansen $M B$, et al. High avidity IFN-neutralizing antibodies in pharmaceutically prepared human lgG. J Clin Invest 1995; $95: 1974-8$

39 Stangel $M$, Schumacher HC, Ruprecht K, et al. Immunoglobulins for intravenous use inhibit TNF- $\alpha$ cytotoxicity in vitro. Immunol Invest 1997:26:569-78.

40 Kondo N, Kasahara K, Kameyma T, et al. Intravenous immunoglobulins suppress immunoglobulin productions by suppressing $\mathrm{Ca}_{2}^{+}$dependent signal transduction through $\mathrm{Fcg}$ receptors on B lymphocytes. Scand J Immunol 1994;40:37-42.

41 Kaveri S, Vassilev T, Hurez V, et al. Antibodies to a conserved region of HLA class I molecules, capable of modulationg CD8 T cell mediated function, are present in pooled normal immunoglobulin for therapeutic use. J Clin Invest 1996;97:865-9.

42 Teeling JL, De Groot ER, Eerenberg AJM, et al. Human intravenous immunoglobulin (IVIG) preparations degranulate human neutrophils in vitro. Clin Exp Immunol 1998; 1 14:264-70.

43 Lutz HU, Stammler P, Jelezarova E, et al. High doses of immunoglobulin G attenuate aggregate-mediated complement activation by enhancing physiologic cleavage of $\mathrm{C} 3 \mathrm{~b}$ in $\mathrm{C} 3 \mathrm{bn}-\mathrm{lgG}$ complexes. Blood 1996:88:184-93.

44 Stangel M, Compston A. Polyclonal immunoglobulins (IVlg) modulate nitric oxide production and microglial functions in vitro via $F_{C}$ receptors. J Neuroimmunol 2001;112:63-71.

45 Stangel M, Compston A, Scolding NJ. Oligodendroglia are protected from antibody mediated complement injury by normal immunoglobulins (IVlg). J Neuroimmunol 2000;103:195-201

46 Warrington AE, Asakura K, Bieber AJ, et al. Human monoclonal antibodies reactive to oligodendrocytes promote remyelination in a model of multiple sclerosis. Proc Natl Acad Sci USA 2000:97:6820-5.

47 Ballow M, Cates KL, Rowe JC, et al. Development of the immune system in very low birth weight (less than $1500 \mathrm{~g}$ ) premature infants: concentrations of plasma immunoglobulins and patterns of infection. Pediatr Res 1986;20:899-904.
48 Baker CJ, Kasper DL. Correlation of maternal antibody deficiency with susceptibility to neonatal group B streptococcal infection. N Engl J Med 1976;294:753-6.

49 Ohlsson A, Lacy JB. Intravenous immunoglobulin for preventing infection in preterm and/or low-birth weight infants [Cochrane review]. In: The Cochrane Library. Oxford: Oxford Update Software, 2002:issue 4.

50 Ohlsson A, Lacy JB. Intravenous immunoglobulin for suspected or subsequently proven infection in neonates [Cochrane review]. In: The Cochrane Library. Oxford: Oxford Update software, 2002:issue 4.

51 Tarnow-Mordi W, Cust A, Brocklehurst $P$, et al. Polyclonal intravenous immunoglobulin to prevent brain injury in preterm infants. Lancet 2002;359:1522

52 Edwards $A D$, Sullivan $M$, Rutherford $M$, et al. Polyclonal intravenous immunoglobulin to prevent brain injury in preterm infants. Lancet 2002;359:1523.

53 Zimmerman JJ. Appraising the potential of pentoxifylline in septic premies. Crit Care Med 1999;27:695-7.

54 Lauterbach R, Pawlik D, Kowalczyk D, et al. Effect of the immuno-modulatory agent pentoxifylline in the treatment of sepsis in prematurely delivered infants: a placebo controlled double-blind trial. Crit Care Med 1999;27:807-14.

55 Lauterbach R, Szymura-Oleksiak J. Nebulized pentoxifylline in successfu treatment of five premature neonates with broncho-pulmonary dysplasia. Eur J Pediatr 1999:158:607.

56 Gasche Y, Copin JC, Sugawara T, et al. Matrix metalloproteinase inhibition prevents oxidative stress-associated blood-brain barrier disruption after transient focal cerebral ischemia. J Cereb Blood Flow Metab 2001;21:1393-400

57 Crowley P. Prophylactic corticosteroids for preterm birth [Cochrane review]. In: The Cochrane Library. Oxford: Oxford Update software, 2002:issue 4.

58 Agarwal A, Chiswick ML, Taylor GM, et al. Antenatal steroids are associated with a reduction in the incidence of cerebral white matter lesions in VLBW infants [abstract]. Arch Dis Child 2002;86(suppl 1):A19.

59 Gray PH, Jones P, O'Callaghan MJ. Maternal antecedents for cerebral palsy in extremely pre-term babies: a case control study. Dev Med Child Neurol 2001;43:580-5.

60 Whitelaw A, Thorensen M. Antenatal steroids and the developing brain. Arch Dis Child Fetal Neonatal Ed 2000;83:F154-7.

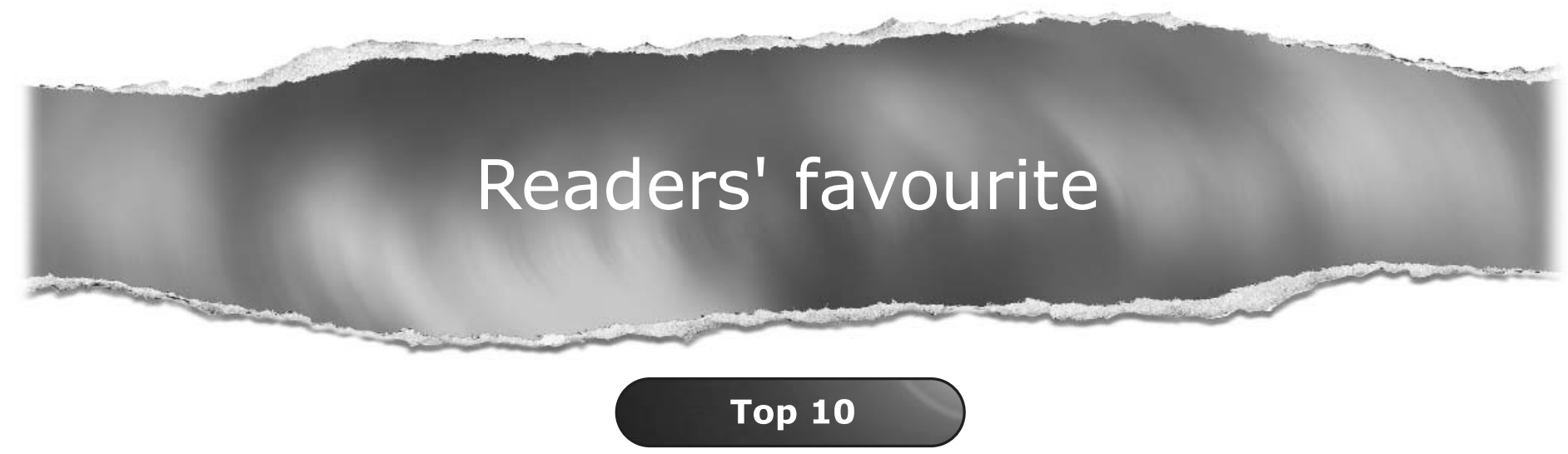

Click on the "Top 10" button on the homepage to see which are the best read articles each month

www.archdischild.com 